\title{
Ergonomic Evaluation and Comparison of Existing and Modified Power Weeder
}

\author{
Suryakanta Khandai ${ }^{1 *}$, Ashok Tripathi ${ }^{1}$, Virendra Kumar ${ }^{2}$, \\ Ashish Kumar Kerketta ${ }^{1}$ and Surendra Pal ${ }^{1}$ \\ ${ }^{1}$ Department of Farm Machinery and Power Engineering, VSAET, SHUATS, India \\ ${ }^{2}$ International Rice Research Institute, Los Banos, Philippines \\ *Corresponding author
}

\section{A B S T R A C T}

\section{Keywords}

Power weeder,

Ergonomic,

Vibration, Noise,

Heart rate, Oxygen

consumption rate

Article Info

Accepted:

17 November 2018

Available Online:

10 December 2018

\begin{abstract}
Power weeder uproots the weeds between the paddy crop rows with $25 \mathrm{~cm}$ row to row distance, in addition to, it keeps the soil surface loose for better soil aeration and water intake capacity. In this study modification was done to existing STIHL power weeder which is operated in line with the attachment of float and covering structure on weeding wheel to avoid mud splash over operator. In this study, the existing weeder and modified weeder has studied ergonomically. 3-axis accelerometer, showed that modified weeder has less vibration of $1.984 \mathrm{~m} / \mathrm{s}^{2}$ from the existing weeder. It was found that average final reading of heart rate for modified power weeder was $101.7 \mathrm{bpm}$ with average initial reading of $95.4 \mathrm{bpm}$ which is comparatively less for existing power weeder having 107.3 bpm with average initial reading of $96.5 \mathrm{bpm}$. The oxygen consumption rate after completion of the operation for modified weeder was $88.8 \mathrm{l} / \mathrm{min}$ and for existing weeder is $91.3 \mathrm{l} / \mathrm{min}$. The noise level for modified weeder was $85.55 \mathrm{db}$ and existing weeder was $89.03 \mathrm{db}$.
\end{abstract}

\section{Introduction}

In all over India weed is a major problem in rice cultivation. There are different methods to control the weeds. The major weed control methods are mechanical, cultural, biological and chemical. In mechanical weeding method, self-propelled power weeder is one of the good options for weeding. Utilizes manual energy, animal power or fuel to run the implements (ranging from khurpi / hand hoe/sickle to multiple tractor drawn or power operated implements) to remove the weeds.
Mechanical weeding is performed by derooting the whole weed plant either by hand tools or by mechanical weeder and are most effective in both dry and wet lands (Nag and Dutt, 1979; Gite and Yadav, 1990; Gite and Yadav, 1985). Mechanical weeding uproots the weeds between rows and helps in loosening the soil surface results in better soil aeration and increase water intake capacity. For every strenuous work in any field requires adequate rest to have an optimum work out put. Better performance results can be expected from both the operator and the 
worker only when proper attention is given for the work rest schedule for different operations.(Sam, 2016) An ergonomic dimension corresponds best to the orientation of the designed machine which are worked in different positions and postures should be different as per the region to meet the requirement of soil type, crop grown, anthropometric measurement's (Sirmour et al., 2018). The present study is mainly focus on power weeder available and suitable for Odisha condition. This type of power weeder is operated by petrol engine and designed by STIHL. The major issue in this type of weeder is having more vibration on human body while operating. So the current machine is modified for ease in operation and also suitable ergonomically. Modification of STIHL power weeder for paddy crop includes the design and fabrication of supporting structure which holds the power weeder considering the optimum vibration on human body, evaluation of its performance with existing weeder in field conditions.

\section{Materials and Methods}

As per agricultural engineering, every machine should be designed ergonomically. The power weeder has a problem of high vibration on human body. The operator has to carry whole weight of the power weeder and oxygen consumption rate, heart rate is high while using the existing power weeder. So the power weeder is modified and tested ergonomically. Vibration is being measured in 3-Axis Accelerometer. Using the uploaded data-collection hardware and software in the accelerometer, one can graph any of these components, or calculate the magnitude of the net acceleration. The accelerometer will get started as follows: 1 . Connect the sensor to the interface where vibration need to measure. 2. The appropriate data-collection software need to start if not already running, and choose new from file menu. After that the software will identify the sensor and load a default datacollection setup. Now the system is ready to continue the experiment.

Fingertip pulse oximeter is the easiest method and being used to measure the heart rate and $\mathrm{SPO}_{2}$. The oximeter is a noninvasive method for monitoring a person's oxygen saturation $\left(\mathrm{SO}_{2}\right)$. In its most common (transmissive) application mode, a sensor device is placed on a fingertip usually a thin part of the body. As a result, device passes two wavelengths of light through the body part to a photodetector. A sound level meter is used to measure the sound wave (sound that travels through air). It is a hand-held instrument and a microphone is attached in the instrument to collect sound wave. The sound waves change the air pressure and the diaphragm of the microphone in sound level meter responds to changes. This is the reason; the instrument is sometimes referred to as a Sound Pressure Level (SPL) Meter.

\section{Results and Discussion}

The modified weeder has better result and suited ergonomically for any operator (Fig. 1).

\section{Effect on vibration}

The main problem identified in existing power weeder is vibration on operator. By using vibration meter, it was found that the overall vibration on the operator by using existing power weeder was $5.733 \mathrm{~m} / \mathrm{s}^{2}$ for the current modified power weeder, overall vibration was $3.749 \mathrm{~m} / \mathrm{s}^{2}$. So it was clear that modified weeder is ergonomically satisfying the operator with less vibration.

\section{Effect on heart rate}

The fingertip oximeter showed that average final reading of heart rate for modified power weeder was $101.7 \mathrm{bpm}$ with average initial 
reading of $95.4 \mathrm{bpm}$ and for existing power weeder was $107.3 \mathrm{bpm}$ with average initial reading of $96.5 \mathrm{bpm}$ as shown in table 1 . This results that modified weeder is user friendly with less heart rate increase in comparison of existing power weeder after completion of operation.

\section{Effect on oxygen consumption rate}

The same fingertip oximeter is also measured oxygen consumption and it showed that average final reading of oxygen consumption rate for modified power weeder was 88.8 $1 /$ min with average initial reading of 85.1
$1 /$ min and for existing power weeder was 91.3 1/min with average initial reading of 89.1 $1 /$ min as shown in table 2 . This results that modified weeder is user friendly with less heart rate increase in comparison of existing power weeder after completion of operation.

\section{Effect on noise}

Noise is also important parameter on ergonomic aspect. For any operator, the noise level should be $85 \mathrm{db}$ and operator can work for more than $1 \mathrm{hr}$ if noise level is $110 \mathrm{db}$. So the noise level was measured and result was shown in table 3 .

Fig.1 3-Axis Accelerometer
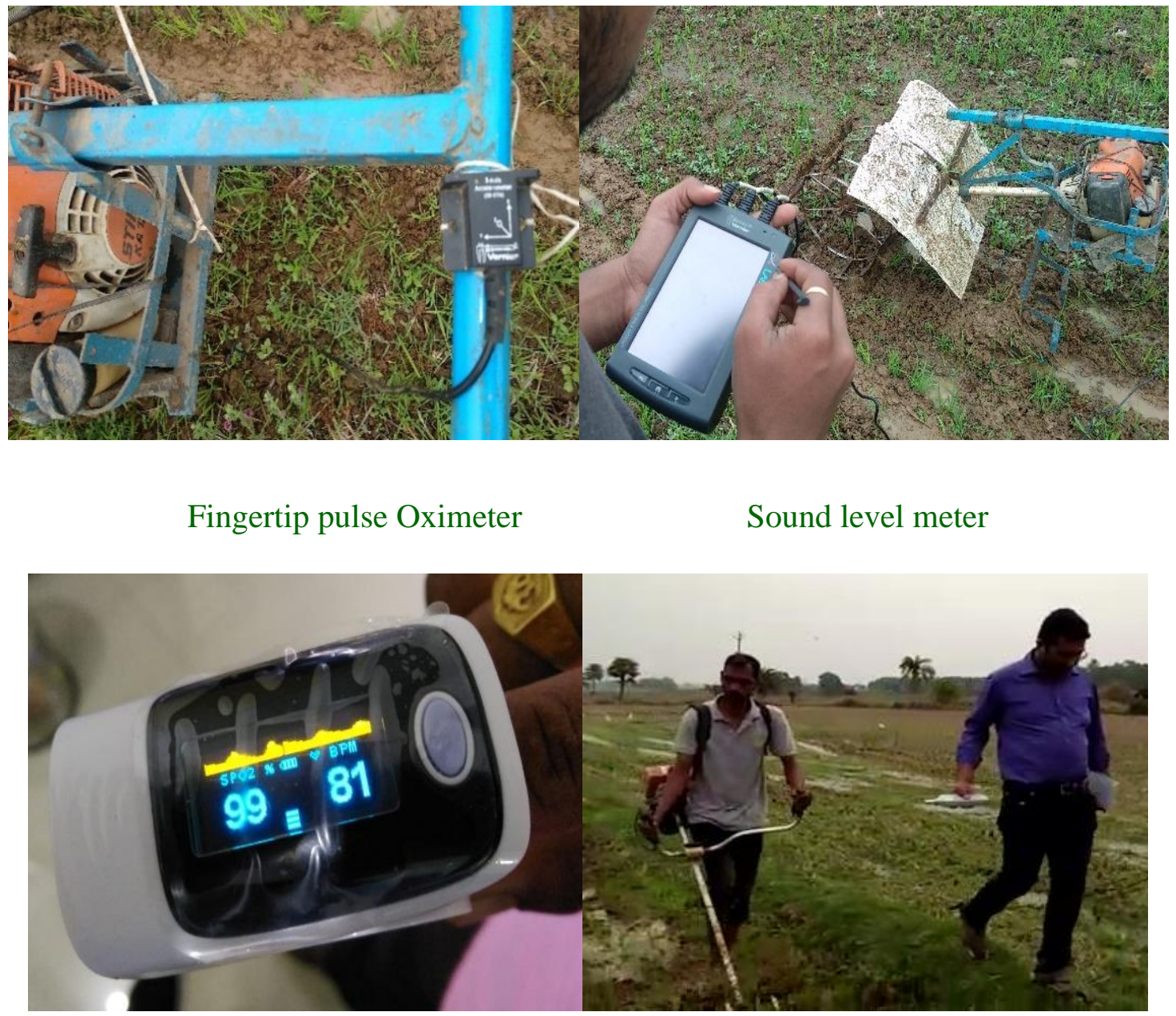


\section{Modified weeder}

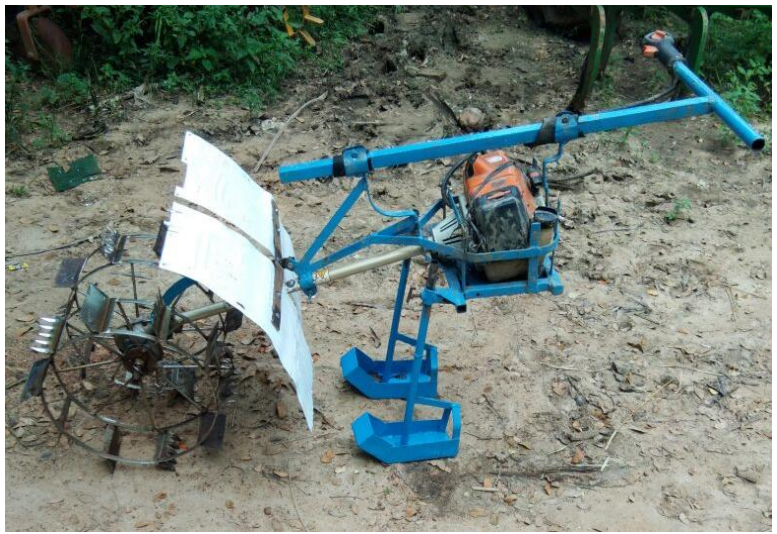

vibration on 3-axis for existing weeder and modified weeder

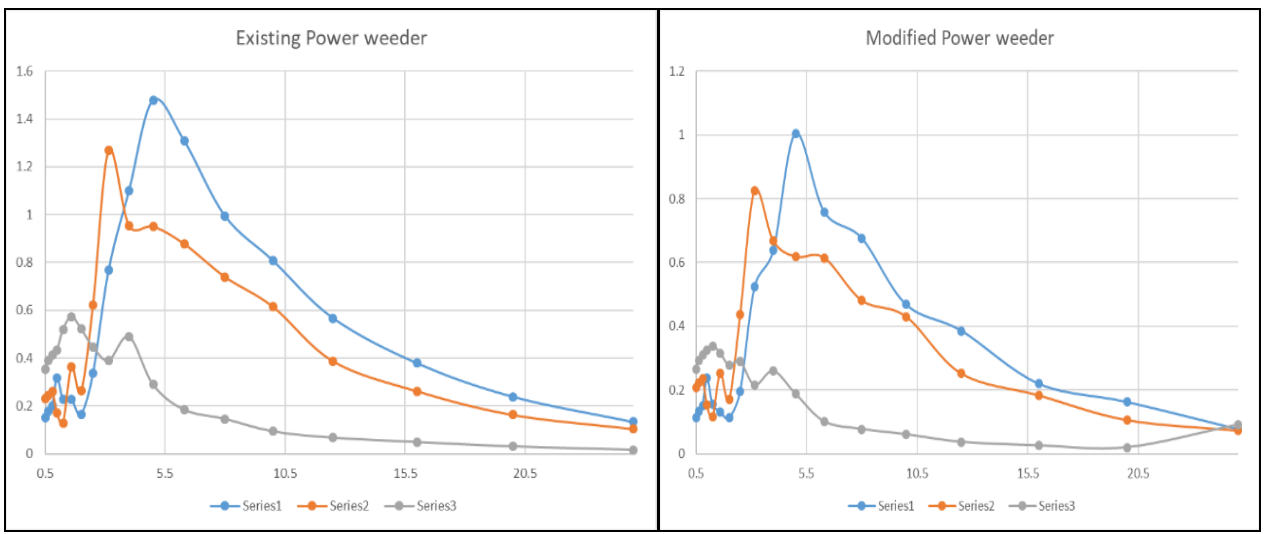

Table.1 Heart rate for existing and modified weeder

\begin{tabular}{|c|c|c|c|c|}
\hline SI No & \multicolumn{2}{|c|}{$\begin{array}{c}\text { Heart rate (bpm) } \\
\text { Existing power weeder }\end{array}$} & \multicolumn{2}{c|}{$\begin{array}{c}\text { Heart rate (bpm) } \\
\text { modified power weeder }\end{array}$} \\
\hline & Initial reading & Final reading & Initial reading & Final reading \\
\hline $\mathbf{1}$ & 92 & 106 & 94 & 102 \\
\hline $\mathbf{2}$ & 90 & 98 & 92 & 95 \\
\hline $\mathbf{3}$ & 90 & 100 & 99 & 104 \\
\hline $\mathbf{4}$ & 100 & 112 & 101 & 109 \\
\hline $\mathbf{5}$ & 106 & 117 & 98 & 105 \\
\hline $\mathbf{6}$ & 95 & 104 & 97 & 101 \\
\hline $\mathbf{7}$ & 94 & 109 & 95 & 100 \\
\hline $\mathbf{8}$ & 96 & 103 & 92 & 99 \\
\hline $\mathbf{9}$ & 102 & 110 & 93 & 100 \\
\hline $\mathbf{1 0}$ & 100 & 114 & 93 & 102 \\
\hline Average & 96.5 & 107.3 & 95.4 & 101.7 \\
\hline
\end{tabular}


Table.2 Oxygen consumption rate for existing and modified weeder

\begin{tabular}{|c|c|c|c|c|}
\hline SI No & \multicolumn{2}{|c|}{$\begin{array}{c}\left.\mathbf{O}_{2} \text { consumption rate } \mathbf{( 1 / m i n}\right) \\
\text { Existing power weeder }\end{array}$} & \multicolumn{2}{|c|}{$\begin{array}{c}\mathbf{O}_{2} \text { consumption rate } \mathbf{( 1 / m i n} \text { ) } \\
\text { modified power weeder }\end{array}$} \\
\hline & Initial reading & Final reading & Initial reading & Final reading \\
\hline $\mathbf{1}$ & 90.1 & 92.3 & 86.7 & 90.4 \\
\hline $\mathbf{2}$ & 88.3 & 90.7 & 82.5 & 87.3 \\
\hline $\mathbf{3}$ & 88.4 & 90.1 & 89.4 & 88.4 \\
\hline $\mathbf{4}$ & 89 & 91.4 & 88.5 & 89.2 \\
\hline $\mathbf{5}$ & 89.2 & 91.9 & 83.4 & 90.2 \\
\hline $\mathbf{6}$ & 89.4 & 91.7 & 84.5 & 90.4 \\
\hline $\mathbf{7}$ & 90.4 & 91.0 & 84.4 & 89.4 \\
\hline $\mathbf{8}$ & 89.1 & 92.1 & 85.6 & 88.1 \\
\hline $\mathbf{9}$ & 88.3 & 90.6 & 82.7 & 87.3 \\
\hline $\mathbf{1 0}$ & 88.6 & 90.9 & 82.9 & 87.6 \\
\hline Average & $\mathbf{8 9 . 1}$ & $\mathbf{9 1 . 3}$ & $\mathbf{8 5 . 1}$ & $\mathbf{8 8 . 8}$ \\
\hline
\end{tabular}

Table.3 Noise level for existing and modified weeder

\begin{tabular}{|c|c|c|}
\hline SI No & $\begin{array}{c}\text { Noise level (db) } \\
\text { Existing power weeder }\end{array}$ & $\begin{array}{c}\text { Noise level }(\mathbf{d b}) \\
\text { modified power weeder }\end{array}$ \\
\hline $\mathbf{1}$ & 90.4 & 86.7 \\
\hline $\mathbf{2}$ & 87.3 & 82.5 \\
\hline $\mathbf{3}$ & 88.4 & 89.4 \\
\hline $\mathbf{4}$ & 89.2 & 88.5 \\
\hline $\mathbf{5}$ & 90.2 & 83.4 \\
\hline $\mathbf{6}$ & 90.4 & 84.5 \\
\hline $\mathbf{7}$ & 89.4 & 84.4 \\
\hline $\mathbf{8}$ & 88.1 & 85.6 \\
\hline $\mathbf{9}$ & 87.3 & 82.7 \\
\hline $\mathbf{1 0}$ & 87.6 & 82.9 \\
\hline $\mathbf{1 1}$ & 87.9 & 84.8 \\
\hline $\mathbf{1 2}$ & 88.9 & 87.5 \\
\hline $\mathbf{1 3}$ & 90.1 & 86.9 \\
\hline $\mathbf{1 4}$ & 90.2 & 84.5 \\
\hline $\mathbf{1 5}$ & 90.0 & 89.0 \\
\hline Average & 89.03 & 85.55 \\
\hline
\end{tabular}

In conclusion, the main problem identified in existing power weeder is vibration on operator. By using vibration meter, it was found that the overall vibration on the operator by using existing power weeder was $5.733 \mathrm{~m} / \mathrm{s}^{2}$ for the current modified power weeder, overall vibration was $3.749 \mathrm{~m} / \mathrm{s}^{2}$. So it was clear that modified weeder is ergonomically satisfy the operator with less vibration.

The fingertip oximeter showed that average 
final reading of heart rate for modified power weeder was $101.7 \mathrm{bpm}$ with average initial reading of $95.4 \mathrm{bpm}$ and for existing power weeder was $107.3 \mathrm{bpm}$ with average initial reading of $96.5 \mathrm{bpm}$. This results that modified weeder is user friendly with less heart rate increase in comparison of existing power weeder after completion of operation.

The same fingertip oximeter is also measured oxygen consumption and it showed that average final reading of oxygen consumption rate for modified power weeder was 88.8 $1 /$ min with average initial reading of 85.1 $1 /$ min and for existing power weeder was 91.3 $1 /$ min with average initial reading of 89.1 $1 / \mathrm{min}$. This results that modified weeder is user friendly with less heart rate increase in comparison of existing power weeder after completion of operation.

\section{References}

Aditya Sirmour, Ajay Verma, Mukesh Pandey and Animesh Chandrawanshi. 2018. Ergonomics Evaluation of Single Row Power Weeder for Rice. Int.J.Curr. Microbiol.App.Sci. 7(01): 681-686.

Bini Sam. January, 2016. Development and Ergonomic Evaluation of a Three Row Power Paddy Weeder for Wet Land Paddy Cultivation. International Journal of Engineering Research and Development. Volume 12, Issue 1, PP.68-73

Dryden, R.D. and Krishnamurthy.1977. Year round tillage. Indian Journal of Weed Science, Vol. 9:14-18.

Gite, L.P. and Yadav, B. G. 1990. Optimum handle height for push-pull type manually operated dry land weeder. Ergonomics, 33.

Gite, L.P. and Yadav, B.G. 1985. Ergonomic consideration in the design of mechanical weeder. Proceedings on Design Course of Agricultural Machines. Central Institute of Agricultural Engineering, Bhopal.

\section{How to cite this article:}

Suryakanta Khandai, Ashok Tripathi, Virendra Kumar, Ashish Kumar Kerketta and Surendra Pal. 2018. Ergonomic Evaluation and Comparison of Existing and Modified Power Weeder. Int.J.Curr.Microbiol.App.Sci. 7(12): 2476-2481. doi: https://doi.org/10.20546/ijcmas.2018.712.281 